\title{
Non-Archimedean Hyers-Ulam Stability of an Additive-Quadratic Mapping
}

\author{
Hassan Azadi Kenary, ${ }^{1}$ Themistocles M. Rassias, $^{2}$ H. Rezaei, ${ }^{1}$ \\ S. Talebzadeh, ${ }^{3}$ and Won-Gil Park ${ }^{4}$ \\ ${ }^{1}$ Department of Mathematics, College of Sciences, Yasouj University, Yasouj 75914-353, Iran \\ ${ }^{2}$ Department of Mathematics, National Technical University of Athens, Zografou Campus, \\ 15780 Athens, Greece \\ ${ }^{3}$ Department of Mathematics, Islamic Azad University, Firoozabad Branch, Firoozabad, Iran \\ ${ }^{4}$ Department of Mathematics Education, College of Education, Mokwon University, \\ Daejeon 302-729, Republic of Korea
}

Correspondence should be addressed to Won-Gil Park, wgpark@mokwon.ac.kr

Received 10 October 2011; Accepted 23 December 2011

Academic Editor: Seenith Sivasundaram

Copyright ( 2012 Hassan Azadi Kenary et al. This is an open access article distributed under the Creative Commons Attribution License, which permits unrestricted use, distribution, and reproduction in any medium, provided the original work is properly cited.

Using fixed point method and direct method, we prove the Hyers-Ulam stability of the following additive-quadratic functional equation $r^{2} f((x+y+z) / r)+r^{2} f((x-y+z) / r)+r^{2} f((x+y-z) / r)+$ $r^{2} f((-x+y+z) / r)=4 f(x)+4 f(y)+4 f(z)$, where $r$ is a positive real number, in non-Archimedean normed spaces.

\section{Introduction and Preliminaries}

A classical question in the theory of functional equations is the following: "When is it true that a function which approximately satisfies a functional equation must be close to an exact solution of the equation?" If the problem accepts a solution, we say that the equation is stable. The first stability problem concerning group homomorphisms was raised by Ulam [1] in 1940. In the next year, Hyers [2] gave a positive answer to the above question for additive groups under the assumption that the groups are Banach spaces. In 1978, Th. M. Rassias [3] proved a generalization of Hyers' theorem for linear mappings. Furthermore, in 1994, a generalization of the Th. M. Rassias' theorem was obtained by Găvruţa [4] by replacing the bound $\epsilon\left(\|x\|^{p}+\|y\|^{p}\right)$ by a general control function $\phi(x, y)$.

In 1983, the Hyers-Ulam stability problem for the quadratic functional equation was proved by Skof [5] for mappings $f: X \rightarrow Y$, where $X$ is a normed space and $Y$ is a Banach 
space. In 1984, Cholewa [6] noticed that the theorem of Skof is still true if the relevant domain $X$ is replaced by an Abelian group and, in 2002, Czerwik [7] proved the Hyers-Ulam stability of the quadratic functional equation. The reader is referred to $[2-4,6-48]$ and references therein for detailed information on stability of functional equations.

In 1897, Hensel [24] has introduced a normed space which does not have the Archimedean property. It turned out that non-Archimedean spaces have many nice applications (see [16, 26-28, 37]).

Definition 1.1. By a non-Archimedean field, one means a field $\mathbb{K}$ equipped with a function (valuation) $|\cdot|: \mathbb{K} \rightarrow[0, \infty)$ such that for all $r, s \in \mathbb{K}$, the following conditions hold:

(1) $|r|=0$ if and only if $r=0$;

(2) $|r s|=|r \| s|$;

(3) $|r+s| \leq \max \{|r|,|s|\}$.

Definition 1.2. Let $X$ be a vector space over a scalar field $\mathbb{K}$ with a non-Archimedean nontrivial valuation $|\cdot|$. A function $\|\cdot\|: X \rightarrow R$ is a non-Archimedean norm (valuation) if it satisfies the following conditions:

(1) $\|x\|=0$ if and only if $x=0$;

(2) $\|r x\|=|r\|\mid x\|(r \in \mathbb{K}, x \in X)$;

(3) the strong triangle inequality (ultrametric), namely,

$$
\|x+y\| \leq \max \{\|x\|,\|y\|\}, \quad x, y \in X
$$

Then $(X,\|\cdot\|)$ is called a non-Archimedean space, due to the fact that

$$
\left\|x_{n}-x_{m}\right\| \leq \max \left\{\left\|x_{j+1}-x_{j}\right\|: m \leq j \leq n-1\right\} \quad(n>m) .
$$

Definition 1.3. A sequence $\left\{x_{n}\right\}$ is Cauchy if and only if $\left\{x_{n+1}-x_{n}\right\}$ converges to zero in a nonArchimedean space. By a complete non-Archimedean space, one means one in which every Cauchy sequence is convergent.

Definition 1.4. Let $X$ be a set. A function $d: X \times X \rightarrow[0, \infty]$ is called a generalized metric on $X$ if $d$ satisfies

(1) $d(x, y)=0$ if and only if $x=y$;

(2) $d(x, y)=d(y, x)$ for all $x, y \in X$;

(3) $d(x, z) \leq d(x, y)+d(y, z)$ for all $x, y, z \in X$.

One recalls a fundamental result in fixed point theory. 
Theorem 1.5 (see $[7,17])$. Let $(X, d)$ be a complete generalized metric space and let $J: X \rightarrow X$ be a strictly contractive mapping with Lipschitz constant $\alpha<1$. Then for each given element $x \in X$, either

$$
d\left(J^{n} x, J^{n+1} x\right)=\infty
$$

for all nonnegative integers $n$ or there exists a positive integer $n_{0}$ such that

(1) $d\left(J^{n} x, J^{n+1} x\right)<\infty$, for all $n \geq n_{0}$;

(2) the sequence $\left\{J^{n} x\right\}$ converges to a fixed point $y^{*}$ of $J$;

(3) $y^{*}$ is the unique fixed point of $J$ in the set $Y=\left\{y \in X \mid d\left(J^{n_{0}} x, y\right)<\infty\right\}$;

(4) $d\left(y, y^{*}\right) \leq(1 /(1-\alpha)) d(y, J y)$ for all $y \in Y$.

In 1998, D. H. Hyers, G. Isac and Th. M. Rassias [25] provided applications of stability theory of functional equations for the proof of new fixed point theorems with applications. By using fixed point methods, the stability problems of several functional equations have been extensively investigated by a number of authors (see [15, 39, 40, 42]).

This paper is organized as follows. In Section 2, using fixed point method, we prove the Hyers-Ulam stability of the following additive-quadratic functional equation:

$$
\begin{array}{rl}
r^{2} f\left(\frac{x+y+z}{r}\right)+r^{2} & f\left(\frac{x-y+z}{r}\right)+r^{2} f\left(\frac{x+y-z}{r}\right)+r^{2} f\left(\frac{-x+y+z}{r}\right) \\
& =4 f(x)+4 f(y)+4 f(z)
\end{array}
$$

where $x, y, z \in X$, in non-Archimedean normed space. In Section 3, using direct method, we prove the Hyers-Ulam stability of the additive-quadratic functional equation (1.4) in nonArchimedean normed spaces.

\section{Stability of the Functional Equation (1.4): A Fixed Point Approach}

In this section, we deal with the stability problem for the quadratic functional equation (1.4).

Theorem 2.1. Let $X$ be a non-Archimedean normed space and $Y$ a complete non-Archimedean space. Let $\varphi: X^{3} \rightarrow[0, \infty)$ be a function such that there exists an $\alpha<1$ with

$$
\frac{1}{|2|} \varphi(2 x, 2 y, 2 z) \leq \alpha \varphi(x, y, z)
$$

for all $x, y, z \in X$. Let $f: X \rightarrow Y$ be an odd mapping satisfying

$$
\begin{aligned}
& \| r^{2} f\left(\frac{x+y+z}{r}\right)+r^{2} f\left(\frac{x-y+z}{r}\right)+r^{2} f\left(\frac{x+y-z}{r}\right) \\
& \quad+r^{2} f\left(\frac{-x+y+z}{r}\right)-4 f(x)-4 f(y)-4 f(z) \|_{Y} \leq \varphi(x, y, z)
\end{aligned}
$$


for all $x, y, z \in X$. Then there exists a unique additive mapping $A: X \rightarrow Y$ such that

$$
\|f(x)-A(x)\|_{Y} \leq \frac{1}{1-\alpha} \max \left\{\frac{\varphi(2 x, 0,0)}{|8|}, \frac{\varphi(x, x, 0)}{|8|}\right\}
$$

for all $x \in X$.

Proof. Note that $f(0)=0$ and $f(-x)=-f(x)$ for all $x \in X$ since $f$ is an odd mapping. Putting $y=z=0$ in (2.2) and replacing $x$ by $2 x$, we get

$$
\left\|r^{2} f\left(\frac{2 x}{r}\right)-2 f(2 x)\right\|_{Y} \leq \frac{1}{|2|} \varphi(2 x, 0,0)
$$

for all $x \in X$. Putting $y=x$ and $z=0$ in (2.2), we have

$$
\left\|r^{2} f\left(\frac{2 x}{r}\right)-4 f(x)\right\|_{Y} \leq \frac{1}{|2|} \varphi(x, x, 0)
$$

for all $x \in X$. By (2.4) and (2.5), we get

$$
\begin{aligned}
\left\|\frac{f(2 x)}{2}-f(x)\right\|_{Y} & \leq \frac{1}{|4|} \max \left\{\left\|r^{2} f\left(\frac{2 x}{r}\right)-2 f(2 x)\right\|_{\gamma^{\prime}}\left\|r^{2} f\left(\frac{2 x}{r}\right)-4 f(x)\right\|_{Y}\right\} \\
& \leq \frac{1}{|8|} \max \{\varphi(2 x, 0,0), \varphi(x, x, 0)\} .
\end{aligned}
$$

Consider the set $S:=\{h: X \rightarrow Y\}$ and introduce the generalized metric on $S$ :

$$
d(g, h)=\inf \left\{\mu \in(0,+\infty):\|g(x)-h(x)\|_{Y} \leq \mu \max \{\varphi(2 x, 0,0), \varphi(x, x, 0)\}, \forall x \in X\right\},
$$

where, as usual, $\inf \phi=+\infty$. It is easy to show that $(S, d)$ is complete (see [31]). Now we consider the linear mapping $J: S \rightarrow S$ such that

$$
J g(x):=\frac{1}{2} g(2 x)
$$

for all $x \in X$. 
Let $g, h \in S$ be given such that $d(g, h)=\lambda$. Then

$$
\|g(x)-h(x)\|_{Y} \leq \lambda \max \{\varphi(2 x, 0,0), \varphi(x, x, 0)\}
$$

for all $x \in X$. Hence

$$
\begin{aligned}
\|J g(x)-J h(x)\|_{Y}=\left\|\frac{1}{2} g(2 x)-\frac{1}{2} h(2 x)\right\|_{Y} & =\frac{1}{|2|}\|g(2 x)-h(2 x)\|_{Y} \\
& \leq \frac{\lambda \max \{\varphi(4 x, 0,0), \varphi(2 x, 2 x, 0)\}}{|2|} \\
& \leq \alpha \lambda \max \{\varphi(2 x, 0,0), \varphi(x, x, 0)\}
\end{aligned}
$$

for all $x \in X$. So $d(g, h)=\lambda$ implies that $d(J g, J h) \leq \alpha \lambda$. This means that $d(J g, J h) \leq \alpha d(g, h)$ for all $g, h \in S$. It follows from (2.6) that

$$
d(f, J f) \leq \frac{1}{|8|}
$$

By Theorem 1.5, there exists a mapping $A: X \rightarrow Y$ satisfying the following.

(1) $A$ is a fixed point of $J$, that is,

$$
2 A(x)=A(2 x)
$$

for all $x \in X$. The mapping $A$ is a unique fixed point of $J$ in the set $M=\{g \in S: d(h, g)<\infty\}$. This implies that $A$ is the unique mapping satisfying (2.12) such that there exists a $\mu \in(0, \infty)$ satisfying $\|f(x)-A(x)\|_{Y} \leq \mu \max \{\varphi(2 x, 0,0), \varphi(x, x, 0)\}$ for all $x \in X$.

(2) $d\left(J^{n} f, A\right) \rightarrow 0$ as $n \rightarrow \infty$. This implies the equality

$$
\lim _{n \rightarrow \infty} \frac{f\left(2^{n} x\right)}{2^{n}}=A(x)
$$

for all $x \in X$.

(3) $d(f, A) \leq(1 /(1-\alpha)) d(f, J f)$, which implies the inequality $d(f, A) \leq 1 /(|8|(1-\alpha))$. This implies that the inequalities (2.3) holds. 
It follows from (2.1) and (2.2) that

$$
\begin{aligned}
& \| r^{2} A\left(\frac{x+y+z}{r}\right)+r^{2} A\left(\frac{x-y+z}{r}\right)+r^{2} A\left(\frac{x+y-z}{r}\right) \\
& +r^{2} A\left(\frac{-x+y+z}{r}\right)-4 A(x)-4 A(y)-4 A(z) \|_{Y} \\
& \quad=\lim _{n \rightarrow \infty} \frac{1}{|2|^{n}} \| r^{2} f\left(\frac{2^{n}(x+y+z)}{r}\right)+r^{2} f\left(\frac{2^{n}(x-y+z)}{r}\right)+r^{2} f\left(\frac{2^{n}(x+y-z)}{r}\right) \\
& \quad+r^{2} f\left(\frac{2^{n}(-x+y+z)}{r}\right)-4 f\left(2^{n} x\right)-4 f\left(2^{n} y\right)-4 f\left(2^{n} z\right) \|_{Y} \\
& \quad \leq \lim _{n \rightarrow \infty} \frac{1}{|2|^{n}} \varphi\left(2^{n} x, 2^{n} y, 2^{n} z\right) \\
& \leq \lim _{n \rightarrow \infty} \alpha^{n} \varphi(x, y, z) \\
& \quad=0
\end{aligned}
$$

for all $x, y, z \in X$. So

$$
\begin{gathered}
r^{2} A\left(\frac{x+y+z}{r}\right)+r^{2} A\left(\frac{x-y+z}{r}\right)+r^{2} A\left(\frac{x+y-z}{r}\right)+r^{2} A\left(\frac{-x+y+z}{s}\right) \\
=4 A(x)+4 A(y)+4 A(z)
\end{gathered}
$$

for all $x, y, z \in X$. Hence $A: X \rightarrow Y$ satisfying (1.4).

It follows from (2.1) and (2.6) that

$$
\begin{aligned}
\|A(2 x)-2 A(x)\|_{Y} & =\lim _{n \rightarrow \infty}\left\|\frac{f\left(2^{n+1} x\right)}{2^{n}}-\frac{2 f\left(2^{n} x\right)}{2^{n}}\right\|_{Y} \\
& \leq \lim _{n \rightarrow \infty} \frac{|2|}{|8||2|^{n}} \max \left\{\varphi\left(2^{n+1} x, 0,0\right), \varphi\left(2^{n} x, 2^{n} x, 0\right)\right\} \\
& \leq \lim _{n \rightarrow \infty} \frac{1}{|4|} \alpha^{n} \max \{\varphi(2 x, 0,0), \varphi(x, x, 0)\}=0
\end{aligned}
$$

for all $x \in X$. So $A(2 x)=2 A(x)$ for all $x \in X$. Hence $A: X \rightarrow Y$ is additive and we get the desired result. 
Corollary 2.2. Let $\theta$ be a positive real number and $q$ a real number with $0<q<1$. Let $f: X \rightarrow Y$ be an odd mapping satisfying

$$
\begin{aligned}
& \| r^{2} f\left(\frac{x+y+z}{r}\right)+r^{2} f\left(\frac{x-y+z}{r}\right)+r^{2} f\left(\frac{x+y-z}{r}\right) \\
& \quad+r^{2} f\left(\frac{-x+y+z}{r}\right)-4 f(x)-4 f(y)-4 f(z) \|_{Y} \leq \theta\left(\|x\|^{q}+\|y\|^{q}+\|z\|^{q}\right)
\end{aligned}
$$

for all $x, y, z \in X$. Then there exists a unique additive mapping $A: X \rightarrow Y$ such that

$$
\|f(x)-A(x)\|_{Y} \leq \frac{2|2|^{q} \theta\|x\|^{q}}{|2|^{q+3}-|2|^{4}}
$$

for all $x \in X$.

Proof. The proof follows from Theorem 2.1 by taking $\varphi(x, y, z)=\theta\left(\|x\|^{q}+\|y\|^{q}+\|z\|^{q}\right)$ for all $x, y, z \in X$. Then we can choose $\alpha=|2|^{1-q}$ and we get the desired result.

Theorem 2.3. Let $X$ be a non-Archimedean normed space and $Y$ a complete non-Archimedean space. Let $\varphi: X^{3} \rightarrow[0, \infty)$ be a function such that there exists an $\alpha<1$ with

$$
|2| \varphi\left(\frac{x}{2}, \frac{y}{2}, \frac{z}{2}\right) \leq \alpha \varphi(x, y, z)
$$

for all $x, y, z \in X$. Let $f: X \rightarrow Y$ be an odd mapping satisfying (2.2). Then there exists a unique additive mapping $A: X \rightarrow Y$ such that

$$
\|f(x)-A(x)\|_{Y} \leq \frac{\alpha}{1-\alpha} \max \left\{\frac{\varphi(2 x, 0,0)}{|8|}, \frac{\varphi(x, x, 0)}{|8|}\right\}
$$

for all $x \in X$.

Proof. Let $(S, d)$ be the generalized metric space defined in the proof of Theorem 2.1. $x \in X$.

Now we consider the linear mapping $J: S \rightarrow S$ such that $J g(x):=2 g(x / 2)$ for all

Replacing $x$ by $x / 2$ in (2.6) and using (2.19), we have

$$
\begin{aligned}
\left\|f(x)-2 f\left(\frac{x}{2}\right)\right\|_{Y} & \leq \frac{1}{|4|} \max \left\{\varphi(x, 0,0), \varphi\left(\frac{x}{2}, \frac{x}{2}, 0\right)\right\} \\
& \leq \frac{\alpha}{|8|} \max \{\varphi(2 x, 0,0), \varphi(x, x, 0)\} .
\end{aligned}
$$

So $d(f, J f) \leq \alpha /|8|$.

The rest of the proof is similar to the proof of Theorem 2.1. 
Corollary 2.4. Let $\theta$ be a positive real number and $q$ a real number with $q>1$. Let $f: X \rightarrow Y$ be an odd mapping satisfying (2.17). Then there exists a unique additive mapping $A: X \rightarrow Y$ such that

$$
\|f(x)-A(x)\|_{Y} \leq \frac{2|2|^{q} \theta\|x\|^{q}}{|2|^{4}-|2|^{q+3}}
$$

for all $x \in X$.

Proof. The proof follows from Theorem 2.3 by taking $\varphi(x, y, z)=\theta\left(\|x\|^{q}+\|y\|^{q}+\|z\|^{q}\right)$ for all $x, y, z \in X$ Then we can choose $\alpha=|2|^{q-1}$ and we get the desired result.

Theorem 2.5. Let $X$ be a non-Archimedean normed space and $Y$ a complete non-Archimedean space. Let $\varphi: X^{3} \rightarrow[0, \infty)$ be a function such that there exists an $\alpha<1$ with

$$
\frac{1}{|4|} \varphi(2 x, 2 y, 2 z) \leq \alpha \varphi(x, y, z)
$$

for all $x, y, z \in X$. Let $f: X \rightarrow Y$ be an even mapping satisfying $f(0)=0$ and (2.2). Then there exists a unique quadratic mapping $Q: X \rightarrow Y$ such that

$$
\|f(x)-Q(x)\|_{Y} \leq \frac{1}{|4|(1-\alpha)} \max \left\{\frac{\varphi(2 x, 0,0)}{|4|}, \frac{\varphi(x, x, 0)}{|2|}\right\}
$$

for all $x \in X$.

Proof. Putting $y=x$ and $z=0$ in (2.2), we have

$$
\left\|r^{2} f\left(\frac{2 x}{r}\right)-4 f(x)\right\|_{Y} \leq \frac{1}{|2|} \varphi(x, x, 0)
$$

for all $x \in X$.

Substituting $y=z=0$ and then replacing $x$ by $2 x$ in (2.2), we obtain

$$
\left\|r^{2} f\left(\frac{2 x}{r}\right)-f(2 x)\right\|_{Y} \leq \frac{1}{|4|} \varphi(2 x, 0,0) .
$$

By (2.25) and (2.26), we get

$$
\begin{aligned}
\left\|\frac{f(2 x)}{4}-f(x)\right\|_{Y} & =\frac{1}{|4|}\left\|r^{2} f\left(\frac{2 x}{r}\right)-4 f(x)-r^{2} f\left(\frac{2 x}{r}\right)+f(2 x)\right\|_{Y} \\
& \leq \frac{1}{|4|} \max \left\{\left\|r^{2} f\left(\frac{2 x}{r}\right)-4 f(x)\right\|_{Y^{\prime}}\left\|r^{2} f\left(\frac{2 x}{r}\right)-f(2 x)\right\|_{Y}\right\} \\
& \leq \frac{1}{|4|} \max \left\{\frac{\varphi(2 x, 0,0)}{|4|}, \frac{\varphi(x, x, 0)}{|2|}\right\} .
\end{aligned}
$$


Consider the set $S^{*}=\{g: X \rightarrow Y ; g(0)=0\}$ and the generalized metric $d^{*}$ in $S^{*}$ defined by

$$
d(g, h)=\inf \left\{\mu \in(0,+\infty):\|g(x)-h(x)\|_{Y} \leq \mu \max \left\{\frac{\varphi(2 x, 0,0)}{|4|}, \frac{\varphi(x, x, 0)}{|2|}\right\}, \forall x \in X\right\},
$$

where, as usual, $\inf \phi=+\infty$. It is easy to show that $\left(S^{*}, d^{*}\right)$ is complete (see [31]).

Now we consider the linear mapping $J:\left(S^{*}, d^{*}\right) \rightarrow\left(S^{*}, d^{*}\right)$ such that $J g(x):=$ $(1 / 4) g(2 x)$ for all $x \in X$.

The rest of the proof is similar to the proof of Theorem 2.1.

Corollary 2.6. Let $\theta$ be a positive real number and $q$ a real number with $q>1$. Let $f: X \rightarrow Y$ be an even mapping satisfying $f(0)=0$ and (2.17). Then there exists a unique quadratic mapping $Q: X \rightarrow$ Y such that

$$
\|f(x)-Q(x)\|_{Y} \leq \frac{1}{|4|-|4|^{q}} \max \left\{\frac{2 \theta\|x\|^{q}}{|2|}, \frac{|2|^{q} \theta\|x\|^{q}}{|4|}\right\}
$$

for all $x \in X$.

Proof. The proof follows from Theorem 2.5 by taking $\varphi(x, y, z)=\theta\left(\|x\|^{q}+\|y\|^{q}+\|z\|^{q}\right)$ for all $x, y, z \in X$. Then we can choose $\alpha=|4|^{q-1}$ and we get the desired result.

Theorem 2.7. Let $X$ be a non-Archimedean normed space and $Y$ a complete non-Archimedean space. Let $\varphi: X^{3} \rightarrow[0, \infty)$ be a function such that there exists an $\alpha<1$ with

$$
|4| \varphi\left(\frac{x}{2}, \frac{y}{2}, \frac{z}{2}\right) \leq \alpha \varphi(x, y, z)
$$

for all $x, y, z \in X$. Let $f: X \rightarrow Y$ be an even mapping satisfying $f(0)=0$ and (2.2). Then there exists a unique quadratic mapping $Q: X \rightarrow Y$ such that

$$
\|f(x)-Q(x)\|_{Y} \leq \frac{\alpha}{|4|(1-\alpha)} \max \left\{\frac{\varphi(2 x, 0,0)}{|4|}, \frac{\varphi(x, x, 0)}{|2|}\right\}
$$

for all $x \in X$.

Proof. It follows from (2.27) that

$$
\begin{aligned}
\left\|f(x)-4 f\left(\frac{x}{2}\right)\right\|_{Y} & \leq \max \left\{\frac{1}{|4|} \varphi(x, 0,0), \frac{1}{|2|} \varphi\left(\frac{x}{2}, \frac{x}{2}, 0\right)\right\} \\
& \leq \frac{\alpha}{|4|} \max \left\{\frac{\varphi(2 x, 0,0)}{|4|}, \frac{\varphi(x, x, 0)}{|2|}\right\} .
\end{aligned}
$$

The rest of the proof is similar to the proof of Theorems 2.1 and 2.5. 
Corollary 2.8. Let $\theta$ be a positive real number and $q$ a real number with $0<q<1$. Let $f: X \rightarrow Y$ be an even mapping satisfying $f(0)=0$ and (2.17). Then there exists a unique quadratic mapping $Q: X \rightarrow Y$ such that

$$
\|f(x)-Q(x)\|_{Y} \leq \frac{|4|^{1-q}}{|4|-|4|^{2-q}} \max \left\{\frac{2 \theta\|x\|^{q}}{|2|}, \frac{|2|^{q} \theta\|x\|^{q}}{|4|}\right\}
$$

for all $x \in X$.

Proof. The proof follows from Theorem 2.7 by taking $\varphi(x, y, z)=\theta\left(\|x\|^{q}+\|y\|^{q}+\|z\|^{q}\right)$ for all $x, y, z \in X$. Then we can choose $\alpha=|4|^{1-q}$ and we get the desired result.

Let $f: X \rightarrow Y$ be a mapping satisfying $f(0)=0$ and (1.4). Let $f_{e}(x):=(f(x)+$ $f(-x)) / 2$ and $f_{o}(x)=(f(x)-f(-x)) / 2$. Then $f_{e}$ is an even mapping satisfying (1.4) and $f_{o}$ is an odd mapping satisfying (1.4) such that $f(x)=f_{e}(x)+f_{o}(x)$. So we obtain the following.

Theorem 2.9. Let $X$ be a non-Archimedean normed space and $Y$ a complete non-Archimedean space. Let $\varphi: X^{3} \rightarrow[0, \infty)$ be a function such that there exists an $\alpha<1$ with

$$
\frac{1}{|4|} \varphi(2 x, 2 y, 2 z) \leq \alpha \varphi(x, y, z)
$$

for all $x, y, z \in X$. Let $f: X \rightarrow Y$ be a mapping satisfying $f(0)=0$ and (2.2). Then there exist an additive mapping $A: X \rightarrow Y$ and a quadratic mapping $Q: X \rightarrow Y$ such that

$$
\begin{aligned}
\| f(x) & -A(x)-Q(x) \|_{Y} \\
& \leq \max \left\{\left\|\frac{f(x)-f(-x)}{2}-A(x)\right\|_{Y} \mid\left\|\frac{f(x)+f(-x)}{2}-Q(x)\right\|_{Y}\right\} \\
& \leq \max \left\{\frac{1}{1-\alpha} \max \left\{\frac{\varphi(2 x, 0,0)}{|8|}, \frac{\varphi(x, x, 0)}{|8|}\right\}, \frac{1}{|4|(1-\alpha)} \max \left\{\frac{\varphi(2 x, 0,0)}{|4|}, \frac{\varphi(x, x, 0)}{|2|}\right\}\right\}
\end{aligned}
$$

for all $x \in X$.

\section{Stability of the Functional Equation (1.4): A Direct Method}

In this section, using direct method, we prove the Hyers-Ulam stability of the additive-quadratic functional equation (1.4) in non-Archimedean space. 
Theorem 3.1. Let $G$ be an additive semigroup and $X$ a non-Archimedean Banach space. Assume that $\zeta: G^{3} \rightarrow[0,+\infty)$ is a function such that

$$
\lim _{n \rightarrow \infty}|2|^{n} \varphi\left(\frac{x}{2^{n}}, \frac{y}{2^{n}}, \frac{z}{2^{n}}\right)=0
$$

for all $x, y, z \in G$. Suppose that, for any $x \in G$, the limit

$$
\Omega(x)=\lim _{n \rightarrow \infty} \max \left\{|2|^{k} \max \left\{\varphi\left(\frac{x}{2^{k}}, 0,0\right), \varphi\left(\frac{x}{2^{k+1}}, \frac{x}{2^{k+1}}, 0\right)\right\} ; 0 \leq k<n\right\}
$$

exists and $f: G \rightarrow X$ is an odd mapping satisfying

$$
\begin{aligned}
& \| r^{2} f\left(\frac{x+y+z}{r}\right)+r^{2} f\left(\frac{x-y+z}{r}\right)+r^{2} f\left(\frac{x+y-z}{r}\right) \\
& \quad+r^{2} f\left(\frac{-x+y+z}{r}\right)-4 f(x)-4 f(y)-4 f(z) \|_{X} \leq \zeta(x, y, z) .
\end{aligned}
$$

Then the limit

$$
A(x):=\lim _{n \rightarrow \infty} 2^{n} f\left(\frac{x}{2^{n}}\right)
$$

exists for all $x \in G$ and defines an additive mapping $A: G \rightarrow X$ such that

$$
\|f(x)-A(x)\| \leq \frac{1}{|4|} \Omega(x)
$$

Moreover, if

$$
\lim _{j \rightarrow \infty} \lim _{n \rightarrow \infty} \max \left\{|2|^{k} \max \left\{\varphi\left(\frac{x}{2^{k}}, 0,0\right), \varphi\left(\frac{x}{2^{k+1}}, \frac{x}{2^{k+1}}, 0\right)\right\} ; j \leq k<n+j\right\}=0,
$$

then $A$ is the unique additive mapping satisfying (3.5).

Proof. By (2.21), we know that

$$
\left\|f(x)-2 f\left(\frac{x}{2}\right)\right\|_{X} \leq \frac{1}{|4|} \max \left\{\varphi(x, 0,0), \varphi\left(\frac{x}{2}, \frac{x}{2}, 0\right)\right\}
$$

for all $x \in$ G. Replacing $x$ by $x / 2^{n}$ in (3.7), we obtain

$$
\left\|2^{n} f\left(\frac{x}{2^{n}}\right)-2^{n+1} f\left(\frac{x}{2^{n+1}}\right)\right\|_{X} \leq \frac{|2|^{n}}{|4|} \max \left\{\varphi\left(\frac{x}{2^{n}}, 0,0\right), \varphi\left(\frac{x}{2^{n+1}}, \frac{x}{2^{n+1}}, 0\right)\right\} .
$$


Thus, it follows from (3.1) and (3.8) that the sequence $\left\{2^{n} f\left(x / 2^{n}\right)\right\}_{n \geq 1}$ is a Cauchy sequence. Since $X$ is complete, it follows that $\left\{2^{n} f\left(x / 2^{n}\right)\right\}_{n \geq 1}$ is convergent. Set

$$
A(x):=\lim _{n \rightarrow \infty} 2^{n} f\left(\frac{x}{2^{n}}\right)
$$

By induction on $n$, one can show that

$$
\left\|2^{n} f\left(\frac{x}{2^{n}}\right)-f(x)\right\|_{X} \leq \frac{1}{|4|} \max \left\{|2|^{k} \max \left\{\varphi\left(\frac{x}{2^{k}}, 0,0\right), \varphi\left(\frac{x}{2^{k+1}}, \frac{x}{2^{k+1}}, 0\right)\right\} ; 0 \leq k<n\right\}
$$

for all $n \geq 1$ and $x \in$ G. Indeed, (3.10) holds for $n=1$ by (3.7). Now, if (3.10) holds for $n$, then by (3.8), we have

$$
\begin{aligned}
& \left\|2^{n+1} f\left(\frac{x}{2^{n+1}}\right)-f(x)\right\| \\
& \quad=\left\|2^{n+1} f\left(\frac{x}{2^{n+1}}\right) \pm 2^{n} f\left(\frac{x}{2^{n}}\right)-f(x)\right\| \\
& \quad \leq \max \left\{\left\|2^{n+1} f\left(\frac{x}{2^{n+1}}\right)-2^{n} f\left(\frac{x}{2^{n}}\right)\right\|,\left\|2^{n} f\left(\frac{x}{2^{n}}\right)-f(x)\right\|\right\} \\
& \quad \leq \frac{1}{|4|} \max \left\{|2|^{n} \max \left\{\varphi\left(\frac{x}{2^{n}}, 0,0\right), \varphi\left(\frac{x}{2^{n+1}}, \frac{x}{2^{n+1}}, 0\right)\right\},\right. \\
& \quad=\frac{1}{|4|} \max \left\{|2|^{k} \max \left\{\varphi\left(\frac{x}{2^{k}}, 0,0\right), \varphi\left(\frac{x}{2^{k+1}}, \frac{x}{2^{k+1}}, 0\right)\right\} ; 0 \leq k<n+1\right\} .
\end{aligned}
$$

By taking $n \rightarrow \infty$ in (3.10) and using (3.2), one obtains (3.5). By (3.1) and (3.3), we get

$$
\begin{aligned}
& \| r^{2} A\left(\frac{x+y+z}{r}\right)+r^{2} A\left(\frac{x-y+z}{r}\right)+r^{2} A\left(\frac{x+y-z}{r}\right) \\
& +r^{2} A\left(\frac{-x+y+z}{r}\right)-4 A(x)-4 A(y)-4 A(z) \|_{X} \\
& \quad=\lim _{n \rightarrow \infty}|2|^{n} \| r^{2} f\left(\frac{x+y+z}{2^{n} r}\right)+r^{2} f\left(\frac{x-y+z}{2^{n} r}\right)+r^{2} f\left(\frac{x+y-z}{2^{n} r}\right) \\
& \quad+r^{2} f\left(\frac{-x+y+z}{2^{n} r}\right)-4 f\left(\frac{x}{2^{n}}\right)-4 f\left(\frac{y}{2^{n}}\right)-4 f\left(\frac{z}{2^{n}}\right) \|_{X} \\
& \leq \lim _{n \rightarrow \infty}|2|^{n} \varphi\left(\frac{x}{2^{n}}, \frac{y}{2^{n}}, \frac{z}{2^{n}}\right) \\
& \quad=0
\end{aligned}
$$


for all $x, y, z \in X$. Therefore, the mapping $A: G \rightarrow X$ satisfies (1.4). we have

To prove the uniqueness property of $A$, let $L$ be another mapping satisfying (3.5). Then

$$
\begin{aligned}
\| A(x) & -L(x) \|_{X} \\
= & \lim _{j \rightarrow \infty}|2|^{j}\left\|A\left(\frac{x}{2^{j}}\right)-L\left(\frac{x}{2^{j}}\right)\right\|_{X} \\
\leq & \lim _{j \rightarrow \infty}|2|^{j} \max \left\{\left\|A\left(\frac{x}{2^{j}}\right)-f\left(\frac{x}{2^{j}}\right)\right\|_{X^{\prime}} \mid\left\|f\left(\frac{x}{2^{j}}\right)-L\left(\frac{x}{2^{j}}\right)\right\|_{X}\right\} \\
\leq & \lim _{j \rightarrow \infty} \lim _{n \rightarrow \infty} \max \left\{|2|^{k} \max \left\{\varphi\left(\frac{x}{2^{k}}, 0,0\right), \varphi\left(\frac{x}{2^{k+1}}, \frac{x}{2^{k+1}}, 0\right)\right\} ; j \leq k<n+j\right\} \\
= & 0
\end{aligned}
$$

for all $x \in G$. Therefore, $A=L$. This completes the proof.

Corollary 3.2. Let $\xi:[0, \infty) \rightarrow[0, \infty)$ be a function satisfying

$$
\xi\left(|2|^{-1} t\right) \leq \xi\left(|2|^{-1}\right) \xi(t), \quad \xi\left(|2|^{-1}\right)<|2|^{-1}
$$

for all $t \geq 0$. Assume that $\kappa>0$ and $f: G \rightarrow X$ is a mapping with $f(0)=0$ such that

$$
\begin{aligned}
& \| r^{2} f\left(\frac{x+y+z}{r}\right)+r^{2} f\left(\frac{x-y+z}{r}\right)+r^{2} f\left(\frac{x+y-z}{r}\right) \\
& \quad+r^{2} f\left(\frac{-x+y+z}{r}\right)-4 f(x)-4 f(y)-4 f(z) \|_{X} \leq \kappa(\xi(\|x\|)+\xi(\|y\|)+\xi(\|z\|))
\end{aligned}
$$

for all $x, y, z \in G$. Then there exists a unique additive mapping $A: G \rightarrow X$ such that

$$
\|f(x)-A(x)\|_{X} \leq \frac{1}{|4|} \max \left\{\kappa \zeta(\|x\|), \frac{2}{|2|} \kappa \zeta(\|x\|)\right\} .
$$

Proof. One can define $\zeta: G^{3} \rightarrow[0, \infty)$ by $\zeta(x, y, z):=\kappa(\xi(\|x\|)+\xi(\|y\|)+\xi(\|z\|))$. Then we have

$$
\lim _{n \rightarrow \infty}|2|^{n} \zeta\left(\frac{x}{2^{n}}, \frac{y}{2^{n}}, \frac{z}{2^{n}}\right) \leq \lim _{n \rightarrow \infty}\left(|2| \xi\left(|2|^{-1}\right)\right)^{n} \zeta(x, y, z)=0
$$

for all $x, y, z \in G$. The last equality comes from the fact that $|2| \xi\left(|2|^{-1}\right)<1$. On the other hand, it follows that

$$
\begin{aligned}
\Omega(x) & =\lim _{n \rightarrow \infty} \max \left\{|2|^{k} \max \left\{\varphi\left(\frac{x}{2^{k}}, 0,0\right), \varphi\left(\frac{x}{2^{k+1}}, \frac{x}{2^{k+1}}, 0\right)\right\} ; 0 \leq k<n\right\} \\
& \leq \max \left\{\varphi(x, 0,0), \varphi\left(\frac{x}{2}, \frac{x}{2}, 0\right)\right\}=\max \left\{\kappa \zeta(\|x\|), \frac{2}{|2|} \kappa \zeta(\|x\|)\right\}
\end{aligned}
$$


exists for all $x \in G$. Also, we have

$$
\begin{aligned}
& \lim _{j \rightarrow \infty} \lim _{n \rightarrow \infty} \max \left\{|2|^{k} \max \left\{\varphi\left(\frac{x}{2^{k}}, 0,0\right), \varphi\left(\frac{x}{2^{k+1}}, \frac{x}{2^{k+1}}, 0\right)\right\} ; j \leq k<n+j\right\} \\
& =\lim _{j \rightarrow \infty}|2|^{j} \max \left\{\varphi\left(\frac{x}{2^{j}}, 0,0\right), \varphi\left(\frac{x}{2^{j+1}}, \frac{x}{2^{j+1}}, 0\right)\right\}=0 .
\end{aligned}
$$

Thus, applying Theorem 3.1, we have the conclusion. This completes the proof.

Theorem 3.3. Let $G$ be an additive semigroup and $X$ a non-Archimedean Banach space. Assume that $\zeta: G^{3} \rightarrow[0,+\infty)$ is a function such that

$$
\lim _{n \rightarrow \infty} \frac{\zeta\left(2^{n} x, 2^{n} y, 2^{n} z\right)}{|2|^{n}}=0
$$

for all $x, y, z \in G$. Suppose that, for any $x \in G$, the limit

$$
\Omega(x)=\lim _{n \rightarrow \infty} \max \left\{\frac{\max \left\{\varphi\left(2^{k+1} x, 0,0\right), \varphi\left(2^{k} x, 2^{k} x, 0\right)\right\}}{|2|^{k}} ; 0 \leq k<n\right\}
$$

exists and $f: G \rightarrow X$ is an odd mapping satisfying (3.3). Then the limit $A(x):=$ $\lim _{n \rightarrow \infty}\left(f\left(2^{n} x\right) / 2^{n}\right)$ exists for all $x \in G$ and

$$
\|f(x)-A(x)\|_{X} \leq \frac{1}{|8|} \Omega(x)
$$

for all $x \in G$. Moreover, if

$$
\lim _{j \rightarrow \infty} \lim _{n \rightarrow \infty} \max \left\{\frac{\max \left\{\varphi\left(2^{k+1} x, 0,0\right), \varphi\left(2^{k} x, 2^{k} x, 0\right)\right\}}{|2|^{k}} ; j \leq k<n+j\right\}=0,
$$

then $A$ is the unique mapping satisfying (3.22).

Proof. By (2.6), we get

$$
\left\|\frac{f(2 x)}{2}-f(x)\right\|_{X} \leq \frac{\max \{\varphi(2 x, 0,0), \varphi(x, x, 0)\}}{|8|}
$$

for all $x \in G$. Replacing $x$ by $2^{n} x$ in (3.24), we obtain

$$
\left\|\frac{f\left(2^{n+1} x\right)}{2^{n+1}}-\frac{f\left(2^{n} x\right)}{2^{n}}\right\|_{X} \leq \frac{\max \left\{\varphi\left(2^{n+1} x, 0,0\right), \varphi\left(2^{n} x, 2^{n} x, 0\right)\right\}}{|2|^{n+3}} .
$$


Thus it follows from (3.20) and (3.25) that the sequence $\left\{f\left(2^{n} x\right) / 2^{n}\right\}_{n \geq 1}$ is convergent. Set

$$
A(x):=\lim _{n \rightarrow \infty} \frac{f\left(2^{n} x\right)}{2^{n}}
$$

On the other hand, it follows from (3.25) that

$$
\begin{aligned}
\left\|\frac{f\left(2^{p} x\right)}{2^{q}}-\frac{f\left(2^{q} x\right)}{2^{q}}\right\|_{X} & =\left\|\sum_{k=p}^{q-1} \frac{f\left(2^{k+1} x\right)}{2^{k+1}}-\frac{f\left(2^{k} x\right)}{2^{k}}\right\|_{X} \\
& \leq \max \left\{\left\|\frac{f\left(2^{k+1} x\right)}{2^{k+1}}-\frac{f\left(2^{k} x\right)}{2^{k}}\right\|_{X} ; p \leq k<q-1\right\} \\
& \leq \frac{1}{|8|} \max \left\{\frac{\max \left\{\varphi\left(2^{k+1} x, 0,0\right), \varphi\left(2^{k} x, 2^{k} x, 0\right)\right\}}{|2|^{k}} ; p \leq k<q\right\}
\end{aligned}
$$

for all $x \in G$ and $p, q \geq 0$ with $q>p \geq 0$. Letting $p=0$, taking $q \rightarrow \infty$ in the last inequality, and using (3.21), we obtain (3.22).

The rest of the proof is similar to the proof of Theorem 3.1. This completes the proof.

Theorem 3.4. Let $G$ be an additive semigroup and $X$ a non-Archimedean Banach space. Assume that $\zeta: G^{3} \rightarrow[0,+\infty)$ is a function such that

$$
\lim _{n \rightarrow \infty}|4|^{n} \varphi\left(\frac{x}{2^{n}}, \frac{y}{2^{n}}, \frac{z}{2^{n}}\right)=0
$$

for all $x, y, z \in G$. Suppose that, for any $x \in G$, the limit

$$
\Theta(x)=\lim _{n \rightarrow \infty} \max \left\{|4|^{k} \max \left\{\frac{1}{|4|} \varphi\left(\frac{x}{2^{k}}, 0,0\right), \frac{1}{|2|} \varphi\left(\frac{x}{2^{k+1}}, \frac{x}{2^{k+1}}, 0\right)\right\} ; 0 \leq k<n\right\}
$$

exists and $f: G \rightarrow X$ is an even mapping satisfying $f(0)=0$ and (3.3). Then the limit $A(x):=$ $\lim _{n \rightarrow \infty} 4^{n} f\left(x / 2^{n}\right)$ exists for all $x \in G$ and defines a quadratic mapping $Q: G \rightarrow X$ such that

$$
\|f(x)-Q(x)\|_{X} \leq \Theta(x)
$$

Moreover, if

$$
\lim _{j \rightarrow \infty} \lim _{n \rightarrow \infty} \max \left\{|4|^{k} \max \left\{\frac{1}{|4|} \varphi\left(\frac{x}{2^{k}}, 0,0\right), \frac{1}{|2|} \varphi\left(\frac{x}{2^{k+1}}, \frac{x}{2^{k+1}}, 0\right)\right\} ; j \leq k<n+j\right\}=0,
$$

then $Q$ is the unique additive mapping satisfying (3.30). 
Proof. It follows from (2.27) that

$$
\left\|f(x)-4 f\left(\frac{x}{2}\right)\right\|_{X} \leq \max \left\{\frac{1}{|4|} \varphi(x, 0,0), \frac{1}{|2|} \varphi\left(\frac{x}{2}, \frac{x}{2}, 0\right)\right\} .
$$

Replacing $x$ by $x / 2^{n}$ in (3.32), we have

$$
\left\|4^{n} f\left(\frac{x}{2^{n}}\right)-4^{n+1} f\left(\frac{x}{2^{n+1}}\right)\right\|_{X} \leq|4|^{n} \max \left\{\frac{1}{|4|} \varphi\left(\frac{x}{2^{n}}, 0,0\right), \frac{1}{|2|} \varphi\left(\frac{x}{2^{n+1}}, \frac{x}{2^{n+1}}, 0\right)\right\} .
$$

It follows from (3.28) and (3.32) that the sequence $\left\{4^{n} f\left(x / 2^{n}\right)\right\}_{n \geq 1}$ is Cauchy sequence.

The rest of the proof is similar to the proof of Theorem 3.1.

Similarly, we can obtain the following. We will omit the proof.

Theorem 3.5. Let $G$ be an additive semigroup and $X$ a non-Archimedean Banach space. Assume that $\zeta: G^{3} \rightarrow[0,+\infty)$ is a function such that

$$
\lim _{n \rightarrow \infty} \frac{\zeta\left(2^{n} x, 2^{n} y, 2^{n} z\right)}{|4|^{n}}=0
$$

for all $x, y, z \in G$. Suppose that, for any $x \in G$, the limit

$$
\Theta(x)=\lim _{n \rightarrow \infty} \max \left\{\frac{1}{|4|^{k}} \max \left\{\frac{1}{|4|} \varphi\left(2^{k+1} x, 0,0\right), \frac{1}{|2|} \varphi\left(2^{k} x, 2^{k} x, 0\right)\right\} ; 0 \leq k<n\right\}
$$

exists and $f: G \rightarrow X$ is an even mapping satisfying $f(0)=0$ and (3.3). Then the limit $Q(x):=$ $\lim _{n \rightarrow \infty}\left(f\left(2^{n} x\right) / 4^{n}\right)$ exists for all $x \in G$ and

$$
\|f(x)-Q(x)\|_{X} \leq \frac{1}{|4|} \Theta(x)
$$

for all $x \in G$. Moreover, if

$$
\lim _{j \rightarrow \infty} \lim _{n \rightarrow \infty} \max \left\{\frac{1}{|4|^{k}} \max \left\{\frac{1}{|4|} \varphi\left(2^{k+1} x, 0,0\right), \frac{1}{|2|} \varphi\left(2^{k} x, 2^{k} x, 0\right)\right\} ; j \leq k<n+j\right\}=0,
$$

then $Q$ is the unique mapping satisfying (3.36).

Let $f: X \rightarrow Y$ be a mapping satisfying $f(0)=0$ and (1.4). Let $f_{e}(x):=(f(x)+$ $f(-x)) / 2$ and $f_{o}(x)=(f(x)-f(-x)) / 2$. Then $f_{e}$ is an even mapping satisfying (1.4) and $f_{o}$ is an odd mapping satisfying (1.4) such that $f(x)=f_{e}(x)+f_{o}(x)$. So we obtain the following. 
Theorem 3.6. Let $G$ be an additive semigroup and $X$ a non-Archimedean Banach space. Assume that $\zeta: G^{3} \rightarrow[0,+\infty)$ is a function such that

$$
\lim _{n \rightarrow \infty} \frac{\zeta\left(2^{n} x, 2^{n} y, 2^{n} z\right)}{|4|^{n}}=0
$$

for all $x, y, z \in G$. Suppose that the limits

$$
\begin{aligned}
& \Omega(x)=\lim _{n \rightarrow \infty} \max \left\{\frac{\max \left\{\varphi\left(2^{k+1} x, 0,0\right), \varphi\left(2^{k} x, 2^{k} x, 0\right)\right\}}{|2|^{k}} ; 0 \leq k<n\right\}, \\
& \Theta(x)=\lim _{n \rightarrow \infty} \max \left\{\frac{\max \left\{\varphi\left(2^{k+1} x, 0,0\right), \varphi\left(2^{k} x, 2^{k} x, 0\right)\right\}}{|4|^{k}} ; 0 \leq k<n\right\}
\end{aligned}
$$

exist for all $x \in G$ and $f: G \rightarrow X$ is a mapping satisfying $f(0)=0$ and (3.3). Then there exist an additive mapping $A: G \rightarrow X$ and a quadratic mapping $Q: G \rightarrow X$ such that

$$
\begin{aligned}
& \|f(x)-A(x)-Q(x)\|_{X} \\
& \leq \max \left\{\left\|\frac{f(x)+f(-x)}{2}-Q(x)\right\|_{X}\left\|\frac{f(x)-f(-x)}{2}-A(x)\right\|_{X}\right\} \\
& \quad \leq \max \left\{\frac{1}{|8|} \Omega(x), \frac{1}{|4|} \Theta(x)\right\}
\end{aligned}
$$

for all $x \in G$. Moreover, if

$$
\begin{gathered}
\lim _{j \rightarrow \infty} \lim _{n \rightarrow \infty} \max \left\{\frac{\max \left\{\varphi\left(2^{k+1} x, 0,0\right), \varphi\left(2^{k} x, 2^{k} x, 0\right)\right\}}{|2|^{k}} ; j \leq k<n+j\right\}=0, \\
\lim _{j \rightarrow \infty} \lim _{n \rightarrow \infty} \max \left\{\frac{1}{|4|^{k}} \max \left\{\frac{1}{|4|} \varphi\left(2^{k+1} x, 0,0\right), \frac{1}{|2|} \varphi\left(2^{k} x, 2^{k} x, 0\right)\right\} ; j \leq k<n+j\right\}=0,
\end{gathered}
$$

then $A$ and $Q$ are the unique mappings satisfying (3.40).

\section{Conclusion}

We linked here three different disciplines, namely, the non-Archimedean normed spaces, functional equations, and fixed point theory. We established the generalized Hyers-Ulam stability of the functional equation (1.4) in non-Archimedean normed spaces.

\section{References}

[1] S. M. Ulam, Problems in Modern Mathematics, Science Editions, John Wiley \& Sons, 1964.

[2] D. H. Hyers, "On the stability of the linear functional equation," Proceedings of the National Academy of Sciences of the United States of America, vol. 27, pp. 222-224, 1941. 
[3] Th. M. Rassias, "On the stability of the linear mapping in Banach spaces," Proceedings of the American Mathematical Society, vol. 72, no. 2, pp. 297-300, 1978.

[4] P. Găvruţa, "A generalization of the Hyers-Ulam-Rassias stability of approximately additive mappings," Journal of Mathematical Analysis and Applications, vol. 184, no. 3, pp. 431-436, 1994.

[5] F. Skof, "Local properties and approximation of operators," Rendiconti del Seminario Matematico e Fisico di Milano, vol. 53, pp. 113-129, 1983.

[6] P. W. Cholewa, "Remarks on the stability of functional equations," Aequationes Mathematicae, vol. 27, no. 1-2, pp. 76-86, 1984.

[7] S. Czerwik, Functional Equations and Inequalities in Several Variables, World Scientific, River Edge, NJ, USA, 2002.

[8] T. Aoki, "On the stability of the linear transformation in Banach spaces," Journal of the Mathematical Society of Japan, vol. 2, pp. 64-66, 1950.

[9] L. M. Arriola and W. A. Beyer, "Stability of the Cauchy functional equation over $p$-adic fields," Real Analysis Exchange, vol. 31, no. 1, pp. 125-132, 2005.

[10] H. Azadi Kenary, “On the stability of a cubic functional equation in random normed spaces," Journal of Mathematical Extension, vol. 4, no. 1, pp. 105-114, 2009.

[11] H. Azadi Kenary and Y. J. Cho, "Stability of mixed additive-quadratic Jensen type functional equation in various spaces," Computers \& Mathematics with Applications, vol. 61, no. 9, pp. 2704-2724, 2011.

[12] H. Azadi Kenary, "Stability of a Pexiderial functional equation in random normed spaces," Rendiconti del Circolo Matematico di Palermo, vol. 60, no. 1-2, pp. 59-68, 2011.

[13] L. Cădariu and V. Radu, "Fixed points and the stability of Jensen's functional equation," Journal of Inequalities in Pure and Applied Mathematics, vol. 4, no. 1, Article ID 4, 2003.

[14] J. K. Chung and P. K. Sahoo, "On the general solution of a quartic functional equation," Bulletin of the Korean Mathematical Society, vol. 40, no. 4, pp. 565-576, 2003.

[15] L. Cădariu and V. Radu, "On the stability of the Cauchy functional equation: a fixed point approach," Grazer Mathematische Berichte, vol. 346, pp. 43-52, 2004.

[16] D. Deses, "On the representation of non-Archimedean objects," Topology and Its Applications, vol. 153, no. 5-6, pp. 774-785, 2005.

[17] J. B. Diaz and B. Margolis, "A fixed point theorem of the alternative, for contractions on a generalized complete metric space," Bulletin of the American Mathematical Society, vol. 74, pp. 305-309, 1968.

[18] M. Eshaghi-Gordji, S. Abbaszadeh, and C. Park, "On the stability of a generalized quadratic and quartic type functional equation in quasi-Banach spaces," Journal of Inequalities and Applications, vol. 2009, Article ID 153084, 26 pages, 2009.

[19] M. Eshaghi-Gordji, S. Kaboli-Gharetapeh, C. Park, and S. Zolfaghari, "Stability of an additive-cubicquartic functional equation," Advances in Difference Equations, vol. 2009, Article ID 395693, 20 pages, 2009.

[20] M. Eshaghi-Gordji, "Nearly ring homomorphisms and nearly ring derivations on non-Archimedean Banach algebras," Abstract and Applied Analysis, vol. 2010, Article ID 393247, 12 pages, 2010.

[21] M. Eshaghi-Gordji and H. Khodaei, "The fixed point method for fuzzy approximation of a functional equation associated with inner product spaces," Discrete Dynamics in Nature and Society, vol. 2010, Article ID 140767, 15 pages, 2010.

[22] M. Eshaghi-Gordji, M. B. Ghaemi, and H. Majani, "Generalized Hyers-Ulam-Rassias theorem in Menger probabilistic normed spaces," Discrete Dynamics in Nature and Society, vol. 2010, Article ID 162371, 11 pages, 2010.

[23] W. Fechner, "Stability of a functional inequality associated with the Jordan-von Neumann functional equation," Aequationes Mathematicae, vol. 71, no. 1-2, pp. 149-161, 2006.

[24] K. Hensel, “Ubereine news Begrundung der Theorie der algebraischen Zahlen, Jahresber," Deutsche Mathematiker-Vereinigung, vol. 6, pp. 83-88, 1897.

[25] D. H. Hyers, G. Isac, and T. M. Rassias, Stability of Functional Equations in Several Variables, Birkhäuser, Basel, Switzerland, 1998.

[26] A. K. Katsaras and A. Beloyiannis, "Tensor products of non-Archimedean weighted spaces of continuous functions," Georgian Mathematical Journal, vol. 6, no. 1, pp. 33-44, 1999.

[27] A. Khrennikov, Non-Archimedean Analysis: Quantum Paradoxes, Dynamical Systems and Biological Models, vol. 427 of Mathematics and its Applications, Kluwer Academic Publishers, Dordrecht, The Netherlands, 1997. 
[28] Z. Kominek, "On a local stability of the Jensen functional equation," Demonstratio Mathematica, vol. 22, no. 2, pp. 499-507, 1989.

[29] S. H. Lee and K.-W. Jun, "Hyers-Ulam-Rassias stability of a quadratic type functional equation," Bulletin of the Korean Mathematical Society, vol. 40, no. 2, pp. 183-193, 2003.

[30] D. Miheț and V. Radu, “On the stability of the additive Cauchy functional equation in random normed spaces," Journal of Mathematical Analysis and Applications, vol. 343, no. 1, pp. 567-572, 2008.

[31] A. K. Mirmostafaee, "Non-Archimedean stability of quadratic equations," Fixed Point Theory, vol. 11, no. 1, pp. 67-75, 2010.

[32] S. A. Mohiuddine, "Stability of Jensen functional equation in intuitionistic fuzzy normed space," Chaos, Solitons \& Fractals, vol. 42, no. 5, pp. 2989-2996, 2009.

[33] S. A. Mohiuddine and H. Ševli, "Stability of Pexiderized quadratic functional equation in intuitionistic fuzzy normed space," Journal of Computational and Applied Mathematics, vol. 235, no. 8, pp. 21372146, 2011.

[34] S. A. Mohiuddine, M. Cancan, and H. Sevli, "Intuitionistic fuzzy stability of a Jensen functional equation via fixed point technique," Mathematical and Computer Modelling, vol. 54, pp. 2403-2409, 2011.

[35] M. Mursaleen and S. A. Mohiuddine, "On stability of a cubic functional equation in intuitionistic fuzzy normed spaces," Chaos, Solitons E Fractals, vol. 42, no. 5, pp. 2997-3005, 2009.

[36] A. Najati and C. Park, "The Pexiderized Apollonius-Jensen type additive mapping and isomorphisms between $C^{*}$-algebras," Journal of Difference Equations and Applications, vol. 14, no. 5, pp. 459-479, 2008.

[37] P. J. Nyikos, "On some non-Archimedean spaces of Alexandroff and Urysohn," Topology and Its Applications, vol. 91, no. 1, pp. 1-23, 1999.

[38] C.-G. Park, "Generalized Hyers-Ulam-Rassias stability of $n$-sesquilinear-quadratic mappings on Banach modules over $C^{*}$-algebras," Journal of Computational and Applied Mathematics, vol. 180, no. 2, pp. 279-291, 2005.

[39] C. Park, "Fixed points and Hyers-Ulam-Rassias stability of Cauchy-Jensen functional equations in Banach algebras," Fixed Point Theory and Applications, vol. 2007, Article ID 50175, 15 pages, 2007.

[40] C. Park, "Generalized Hyers-Ulam stability of quadratic functional equations: a fixed point approach," Fixed Point Theory and Applications, vol. 2008, Article ID 493751, 9 pages, 2008.

[41] J. C. Parnami and H. L. Vasudeva, “On Jensen's functional equation,” Aequationes Mathematicae, vol. 43, no. 2-3, pp. 211-218, 1992.

[42] V. Radu, "The fixed point alternative and the stability of functional equations," Fixed Point Theory, vol. 4, no. 1, pp. 91-96, 2003.

[43] R. Saadati, S. M. Vaezpour, and Y. J. Cho, "A note to paper 'On the stability of cubic mappings and quartic mappings in random normed spaces'," Journal of Inequalities and Applications, vol. 2009, Article ID 214530, 6 pages, 2009.

[44] R. Saadati and C. Park, "Non-Archimedean L-fuzzy normed spaces and stability of functional equations," Computers \& Mathematics with Applications, vol. 60, no. 8, pp. 2488-2496, 2010.

[45] R. Saadati and J. H. Park, “On the intuitionistic fuzzy topological spaces," Chaos, Solitons and Fractals, vol. 27, no. 2, pp. 331-344, 2006.

[46] S.-S. Zhang, R. Saadati, and G. Sadeghi, "Solution and stability of mixed type functional equation in non-Archimedean random normed spaces," Applied Mathematics and Mechanics, vol. 32, no. 5, pp. 663-676, 2011.

[47] S.-S. Zhang, M. Goudarzi, R. Saadati, and S. M. Vaezpour, "Intuitionistic Menger inner product spaces and applications to integral equations," Applied Mathematics and Mechanics, vol. 31, no. 4, pp. 415-424, 2010.

[48] S.-S. Zhang, J. M. Rassias, and R. Saadati, "Stability of a cubic functional equation in intuitionistic random normed spaces," Applied Mathematics and Mechanics, vol. 31, no. 1, pp. 21-26, 2010. 


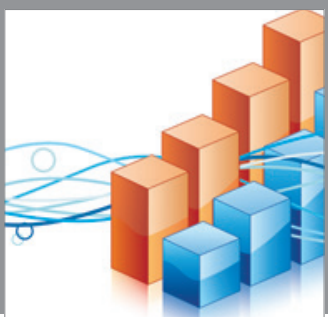

Advances in

Operations Research

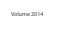

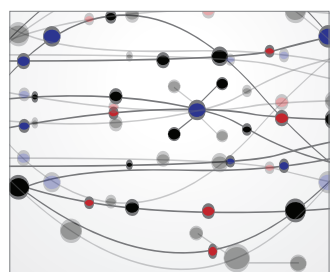

\section{The Scientific} World Journal
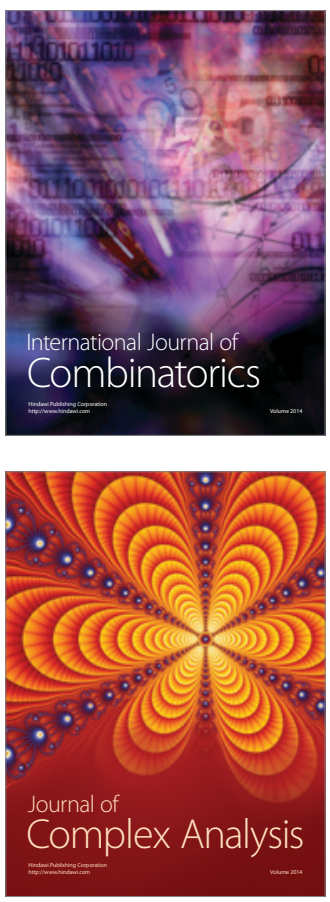

International Journal of

Mathematics and

Mathematical

Sciences
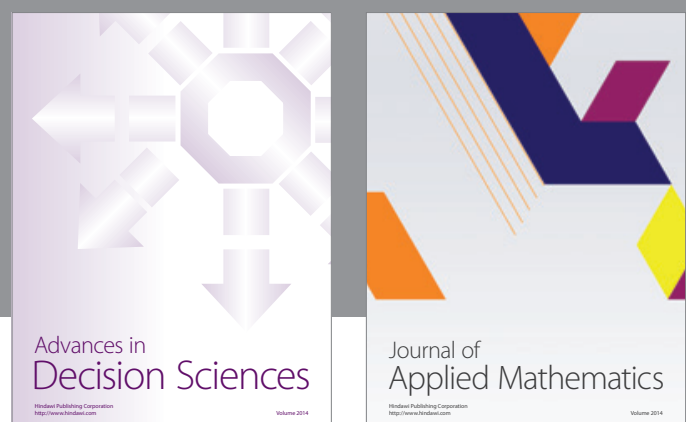

Journal of

Applied Mathematics
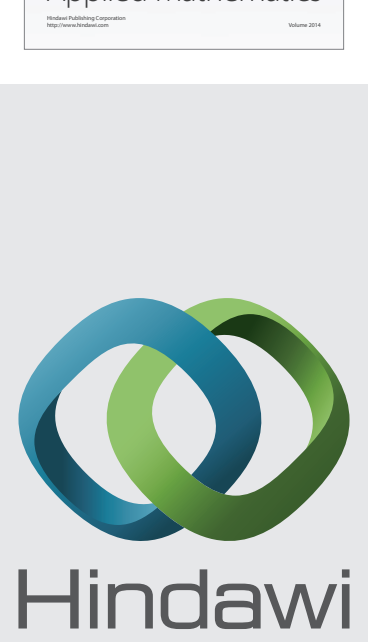

Submit your manuscripts at http://www.hindawi.com
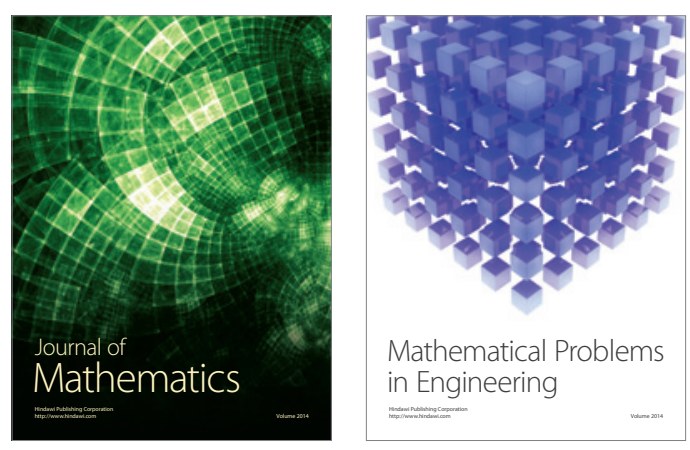

Mathematical Problems in Engineering
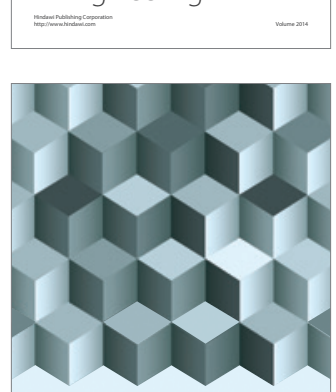

Journal of

Function Spaces
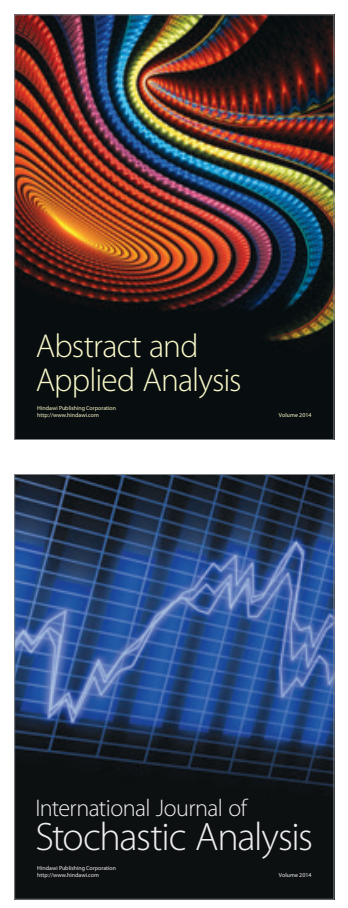

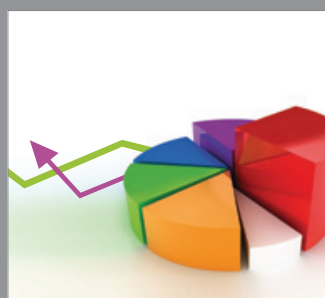

ournal of

Probability and Statistics

Promensencen
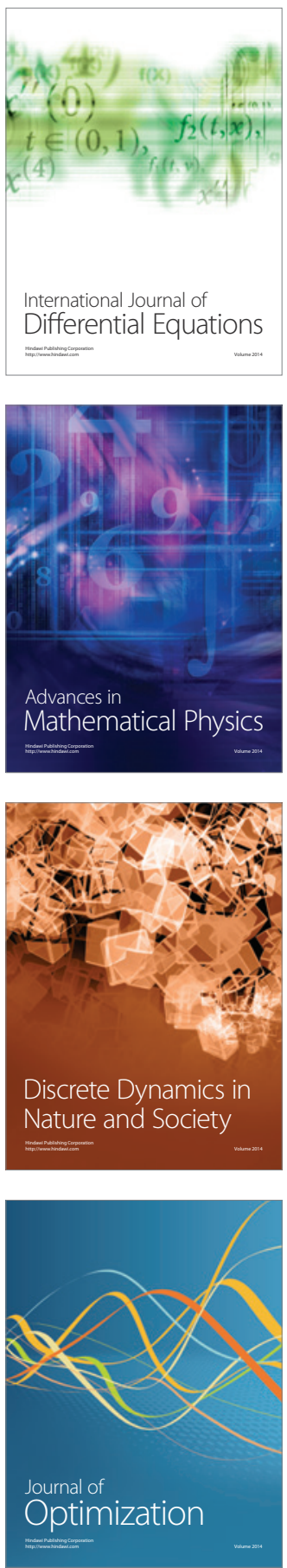